\title{
Helmut Geller
}

Position - Rolle - Situation 


\section{Helmut Geller}

Position

Rolle

Situation

Zur Aktualisierung soziologischer

Analyseinstrumente

Leske + Budrich, Opladen 1994 
ISBN 978-3-322-95982-9 ISBN 978-3-322-95981-2 (eBook)

DOI 10.1007/978-3-322-95981-2

(C) 1994 by Leske + Budrich, Opladen

Das Werk einschließlich aller seiner Teile ist urheberrechtlich geschützt. Jede Verwertung außerhalb der engen Grenzen des Urheberrechtsgesetzes ist ohne Zustimmung des Verlags unzulässig und strafbar. Das gilt insbesondere für Vervielfältigungen, Übersetzungen, Mikroverfilmungen und die Einspeicherung und Verarbeitung in elektronischen Systemen.

Satz: Leske + Budrich 


\section{Inhaltsverzeichnis}

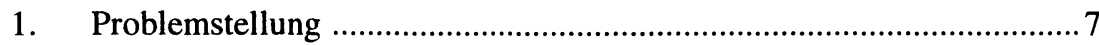

$1.1 \quad$ Anlaß für einen Rückgriff auf die Rollentheorie................................... 7

1.2 Grenzen und Unklarheiten der rollentheoretischen Ansätze ..................9

1.3 Interaktions- und organisierte Sozialsysteme ................................... 12

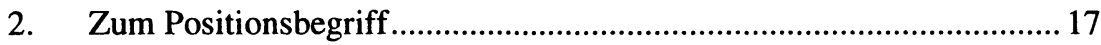

2.1 Das Grundkonzept "Rolle und Status" bei R. Linton ......................... 17

2.2 Arbeitsteilung als Bedingung für die Schaffung von Positionen ........ 20

2.3 Erwartungen, Normen, Institutionen ................................................. 24

2.4 Relevanzsysteme als institutionalisierte Regelsysteme .....................30

2.5 Umschreibung des Positionsbegriffes …............................................. 33

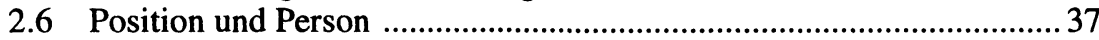

2.7 Zum Horizontcharakter von Positionsgrenzen ................................... 46

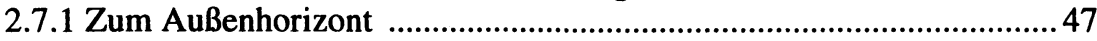

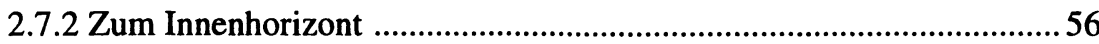

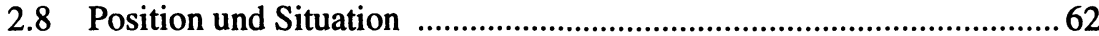

2.9 Zur Verflechtung von Positionen .......................................................67

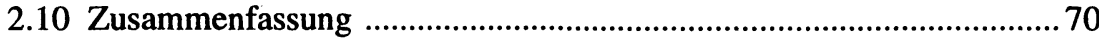

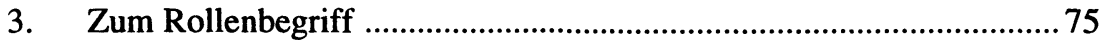

3.1 Persönlichkeitsstrukturen als strukturelle Entscheidungsprämissen

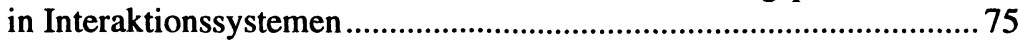

3.2 Status als Zuschreibungsmechanismus in Interaktionssystemen..........80 
4. "Der Stand der Dinge" als Entscheidungsprämisse in Interaktionssystemen .88 Exkurs: Situations-, Positions- und Statusrollen nach U. Gerhardt.......97

5. Allgemeine Qualifikationsanforderungen an Rollenpieler ................ 102

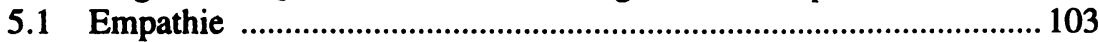

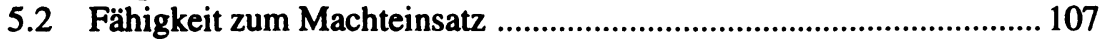

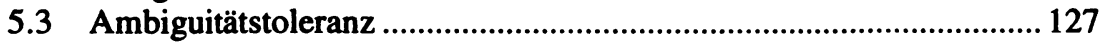

5.4 Fähigkeit zur Informationskontrolle............................................... 136

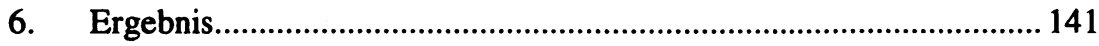

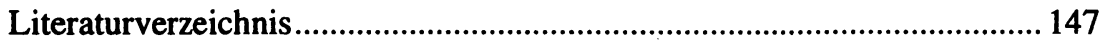

